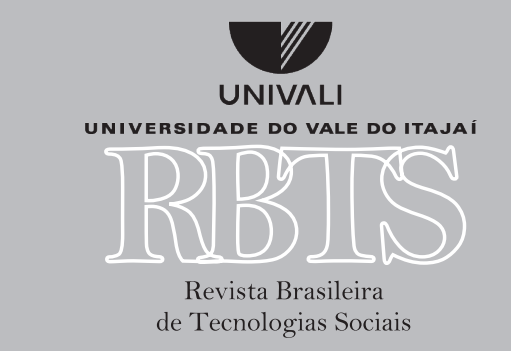

1 Bacharel em Direito pela Universidade de Cruz Alta/UNICRUZ. E-mail: alineromaninis@hotmail.com 2 Advogada. Mestre em Direito (UNISC/RS). Doutoranda em Diversidade Cultural e Inclusão Social na Universidade FEEVALE/RS. Bolsista PROSUP/ CAPES. |E-mail: maricamargod@ gmail.com
Revista Brasileira de Teonologias Sociais, v.3, n.2, 2016

doi: 10.142 $16 /$ rbts.v3.n1.p3-12

ARTigos

\section{Segredos intrafamiliares: violências psicológica e simbólica contra a mulher}

\section{Family secrects: psychological and symbolic violence against women}

\author{
Aline Romanini da Silva ${ }^{1 ;}$ Mariane Camargo D’OLIVEIRA ${ }^{2}$
}

RESUMO: A violação dos direitos femininos é uma problemática cada dia mais presente na rotina de inúmeras mulheres e, não raras vezes, desconhecida pelas próprias vítimas. Nesse sentido, indaga-se: a estratégia de ocultação da violência psicológica e simbólica intrafamiliar contra a mulher é fortificada pelo mecanismo do segredo? Assim, o objetivo geral é analisar os mecanismos que influenciam para a não visibilização do segredo intrafamiliar, a fim de verificar as razões que contribuem para o ocultamento das violências simbólica e psicológica no âmbito doméstico. É um estudo de caráter qualitativo e de cunho empírico, pois foi realizada uma coleta de dados de alguns Inquéritos Policiais, no período de janeiro de 2015 a março de 2016, oriundos da Delegacia de Polícia Especializada no Atendimento à Mulher de Cruz Alta/RS.

Palavras-Chave: Autonomia. Gênero. Visibilização. Silenciamento. Submissão.

ABSTRACT: The violation of women's rights is an increasingly prevalent problem in the daily lives of countless women, but often goes unnoticed, even by the victims themselves. We therefore ask the question: is the strategy of concealing psychological and symbolic violence against women within the family bolstered by the mechanism of secrecy? The general aim of this work is to analyze the mechanisms that influence the non-visualization of family secrets, seeking to elucidate the factors that contribute to the concealment of symbolic and psychological violence in the home. This is a qualitative study of an empirical nature, conducted through the collection of data from police investigations conducted in the period from January 2015 to March 2016, by the Specialized Police Department for Assistance to Women in Cruz Alta/RS.

Key Words: Autonomy. Gender. Visualization. Silencing. Submission. 
UNIVALI

UNIVERSIDADE DO VALE DO ITAJAÍ

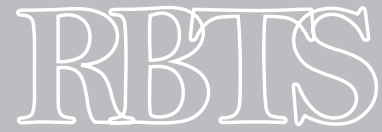

Revista Brasileira de Tecnologias Sociais 


\section{CONSIDERAÇÕES INICIAIS}

É necessário elucidar, para uma compreensão mais adequada da temática que se pretende investigar, que a violência intrafamiliar é aquela que acontece entre indivíduos com vínculos afetivos, sociais e, até mesmo, econômicos. Estas relações são originadas por encadeamentos sentimentais, familiares ou, apenas, por coabitação. Contudo, não raras vezes, o emocional dá lugar ao violento, sendo que tal violência é gerada por ação ou omissão daqueles que deveriam resguardar, zelar e, principalmente, respeitar a vida da mulher. Referidas atitudes destinam-se a deteriorar, manipular comportamentos e crenças, além de oprimir e subjugar. De um modo geral, ocorrem através de ameaças, diretas ou indiretas, e ações violentas, ao se humilhar e se isolar o sujeito, ferindo, de uma maneira cruel, a saúde emocional, física e psicológica, bem como o desenvolvimento interpessoal da mulher-vítima.

Já a violência de caráter simbólico consiste na dominação social, cultural, política e econômica do gênero feminino, pois a mulher não percebe como estes mecanismos de sujeição estão implícita e explicitamente expostos, por meio de pensamentos, gostos, gestos e atitudes cotidianas cometidas pelo próprio arranjo familiar, pelo contexto profissional, pelos ambientes midiáticos, pelas instituições religiosas e também pelo Estado, já que há uma interferência na construção de significados e de sentidos. É nesse processo de socialização que a violência simbólica vai sendo perpetrada, ao considerar que as próprias mulheres são agentes de permanência das práticas que produzem e reproduzem o discurso patriarcal da dominação masculina.

Nesse sentido, é necessário indagar: a estratégia de ocultação das violências psicológica e simbólica intrafamiliar contra a mulher é fortificada pelo mecanismo do segredo? Assim, o objetivo geral da presente pesquisa é analisar os mecanismos que influenciam para a não visibilização do segredo intrafamiliar, a fim de examinar as razões que contribuem para o ocultamento das violências simbólica e psicológica no âmbito doméstico.

Dessa forma, para o estudo, de cunho qualitativo, foi realizada uma coleta de dados de alguns Inquéritos Policiais, no período de janeiro de 2015 a março de 2016, oriundos da Delegacia de Polícia Especializada no Atendimento à Mulher de Cruz Alta/RS, com o apoio da Dra. Carolina Sanfelice Mariani, Promotora da $2^{a}$ Vara Criminal desta Comarca. Tudo isto para que fosse possível diagnosticar o perfil da vítima de violência psicológica e simbólica na cidade, avaliando como tal representação resulta na subjugação e no segredo intrafamiliar.

\section{CONCEPÇÕES DE VIOLÊNCIA PSICOLÓGICA E SIMBÓLICA}

As situações de violência contra a mulher, principalmente no ambiente intrafamiliar, continuam a crescer e, em cada caso, por mais diverso que seja o delito, o maior índice de ofendidas possui um patamar parecido quanto às variáveis socioeconômicas (RIBEIRO, 2013, p. 62-63). Nesse caminho, Narvaz e Koller (2006, p. 647-654) caracterizam os tipos de violência, sendo a violência doméstica aquela que engloba todas as pessoas de um mesmo grupo, não tendo a necessidade de grau de parentesco, mas sim o convívio no espaço doméstico. Por sua vez, a violência intrafamiliar é mais ampla, referindo-se à omissão ou à ação, que cause danos e prejuízo à saúde mental, física, emocional de outrem, com ou sem laços sanguíneos, mas que faça parte ou assuma um papel no arranjo familiar.

A violência contra a mulher tem ganhado grande notoriedade pelo mundo, por conta dos diversos efeitos devastadores que este fenômeno causa sobre a pessoa humana. Então, as políticas 
públicas passaram a ser alternativas viáveis como meios de socorro à toda ofendida e à sua família. Isso se deve em razão de que a violência familiar pode ser analisada como toda ação ou omissão cometida no seio de uma família por um de seus membros, ameaçando a vida, a integridade física ou psíquica, incluindo a liberdade, causando sérios danos ao desenvolvimento de sua personalidade. Nesse fenômeno, existem três variáveis (o gênero, a idade e a circunstância de desproteção) que são decisivas na hora de estabelecer a distribuição de poder e, consequentemente, determinar a direção que adota a conduta violenta, bem como quem são as vítimas mais frequentes, de acordo com Jesus (2015).

Seguindo tal entendimento, Safiotti (1999a, p. 83) explica que, "compreendida na violência de gênero, a violência familiar pode ocorrer no interior do domicílio ou fora dele, embora seja mais frequente o primeiro caso. A violência intrafamiliar extrapola os limites do domicílio". A partir destas ideias, é possível compreender que a violência física, sexual e moral não acontece sozinha, sendo que a violência psicológica e moral está sempre presente, mesmo que de maneira indireta, uma vez que, quando se fere alguém, o emocional se torna o primeiro ponto da agressividade. $\mathrm{O}$ abalo não é apenas de cunho físico, com gestos e agressões corporais, mas também com palavras e, até mesmo, com o silêncio. Uma mulher que não é respondida magoa-se e, quando isto se torna parte da rotina, é seu psicológico que está sendo afetado. Tal agressão é silenciosa e, na maioria dos casos, a própria ofendida não percebe que está sendo lesada (PATEMAN, 1993; SAFFIOTI, 1987; MARQUES, 2005).

Perfilhando tal percepção, a violência psicológica é do que o ato ou omissão, através de gestos ou palavras, para ferir a outra pessoa, causando dano à autoestima e ao desenvolvimento psíquico, sendo suas ações amplas e decorrentes de humilhações, injúrias, ameaças, ofensas, rejeições, privações da liberdade e explorações. Conduz, assim, a vítima a uma efetiva e infeliz desvalorização do próprio indivíduo, bem como a doenças psicológicas e físicas, pois com o enfraquecimento psicológico, o sujeito torna-se ainda mais propenso e mais exposto a diversas outras patologias (ZANCAN; WASSERMANN; LIMA, 2013).

Desse modo, a aludida violência ultrapassa diversas barreiras sociais, uma vez que é vista e sentida por mulheres de todas as classes, porém pouquíssimas são as que realmente notam sua concretização. Isto porque ainda permanece o estigma de que a violência só existe quando é visível por marcas físicas ou testemunhas. E que a violência psicológica intrafamiliar, na maioria dos casos, apenas tem como testemunha a própria ofendida, que, a cada episódio, se torna mais enfraquecida quando, calada, consente, de uma maneira indireta, as atrocidades que está vivenciando em seu cotidiano. Nessa direção, Silva, Coelho e Caponi (2007) reforçam que, muitas vezes, a própria vítima não reage às agressões, não as reconhece como nocivas, visto que julga seu estado emocional e seus sentimentos como resultados de outros fatores, não relacionando suas dores às agressões feitas pelo companheiro.

Além da violência psicológica, contribui para perpetuar a subjugação feminina, a violência simbólica, que é constante e muito atuante em todos os contextos sociais. Para Bourdieu (1989, p. 08-21), tal violência é aquela empregada pelo detentor do poder, com o consentimento, ainda que indireto, daquela que se torna vítima. É necessário saber descobri-la onde esta se deixa ver menos, onde esta é mais completamente ignorada, portanto, não reconhecida. O poder simbólico é, com efeito, esse poder invisível o qual só pode ser exercido com a cumplicidade daqueles que não querem saber que lhe estão sujeitos ou mesmo que o exercem. Sob referido prisma, a dominação masculina é um caso particular de violência simbólica. Desse jeito é possível compreender “a 
dominação masculina como fruto de práticas sociais (violentas) concretas e cotidianas e que as mudanças nestas práticas implicam mudanças no âmbito simbólico” (CLIMACO, 2008, p. 440).

Pode-se concluir, pelo confrontado, que a violência psicológica e a simbólica, conjugadas, conduzem a um processo de enfraquecimento da mulher-vítima, ao vislumbrar que esta não percebe, efetivamente, a relação de submissão-exploração-dominação que está vivenciando e, por isso mesmo, vai tornando-a, de modo diuturno, natural. Assim, a escolha por visibilizar as duas violências foi no sentido de que estas se configuram em um fato crucial para que o sistema patriarcal e de dominação masculina não seja rompido completamente.

\section{O OCULTAMENTO DOS SEGREDOS INTRAFAMILIARES}

A vítima das violências psicológica e simbólica, não raras vezes, busca o silêncio e a negação como aliados para enfrentar as constantes agressões familiares. Negam o que ouviram e, na sequência, culpam-se pelo que está acontecendo, deixando o agressor no patamar hierárquico, ao não se vitimizarem e, sim, se culpabilizarem. Nessa ótica, os segredos vão se consolidando em decorrência dos medos, das retaliações, da pouquíssima ciência sobre as políticas públicas, bem como do desconhecimento do direito de ser livre e da proteção que a mulher tem na forma da Lei n. ${ }^{\circ}$ 11.340/2006, a conhecida "Lei Maria da Penha", que possui como princípio norteador fundamental a salvaguarda das desigualdades de gêneros.

Por meio da análise de dados fornecidos por 80 inquéritos policiais oriundos da $2^{\text {a }}$ Promotoria Criminal, referentes à Comarca de Cruz Alta/RS, foi possível traçar, de maneira simplificada, o perfil da mulher-vítima cruz-altense. Para tanto, os elementos examinados foram os seguintes: a idade da ofendida, quantos descendentes, o número de dependentes, o tempo de convivência, a escolaridade, a profissão e o vínculo com o agressor. Tudo isso a fim de que se pudesse chegar a um consenso sobre quem é a mulher que procura ajuda, para, assim, tentar viabilizar compreensões mais adequadas sobre a violência familiar ocorrida.

É fundamental destacar de que se trata de um diagnóstico parcial, segmentado, que pode não conduzir a uma descrição completa e total das mulheres-vítima da cidade, até mesmo porque foram observados somente 80 inquéritos, no período de janeiro de 2015 a março de 2016 . Sabe-se que a questão da violência de gênero envolve um emaranhado de fatores muito mais complexos de se mensurar além daqueles que agora serão explanados. E isso denota o quanto são indispensáveis pesquisas nesse campo.

Consoante os dados obtidos, as vítimas que registraram ocorrência na Delegacia Especializada de Atendimento à Mulher (DEAM) de Cruz Alta/RS possuem idade entre 23 a 27 anos, o que enfatiza como as jovens acabam por se vincular a relacionamentos violentos em período, de certa forma, precoce. Em relação a este aspecto, Sá (2011) menciona que se trata de mulheres que estão em época fértil e ativa, o que significa dizer que se encontram na faixa etária ideal para o desenvolvimento sociofamiliar e econômico.

A maioria não possui descendentes e nem dependentes. O que, novamente, enfatiza a possibilidade de desvinculação com o agressor, pois quando há dependentes ou vínculos que duram a vida toda com o homem, as vítimas tendem a pensar nos filhos e, posteriormente, em sua vida, porque entendem que o bem-estar da família se sobrepõe ao seu próprio livre arbítrio (FERNANDES, 2012; RIBEIRO, 2013). Nesse campo, o número de descendentes e nem o de dependentes é fator que influencia o rompimento do ciclo da violência. 
Ademais, deve-se ressaltar que, apesar de o índice de semianalfabetizadas ser ínfimo, apenas 9\% concluíram o Ensino Superior. A maioria apenas cursou o Ensino Fundamental. Como já referido, a grande parcela das vítimas refere-se a mulheres jovens e em idade ativa. Assim, a baixa escolaridade é um dado bem preocupante. Tais dados vão ao encontro dos obtidos na pesquisa de Moura, Albuquerque Netto e Souza (2012), o que reforça que a violência intrafamiliar se espalha por todo o país. Os fatores que caracterizam a mulher como submissa são comuns em todas as regiões. O baixo nível de escolaridade, associado às profissões que pouco favorecem seu empoderamento, acarreta o fortalecimento da subordinação.

Por meio desse apanhado, mesmo que simplificado dos dados informados no cadastro Maria da Penha, evidencia que o perfil da vítima tem muito a ver com a dependência econômica. Isto é, apesar de serem mulheres jovens, sem dependentes, o nível de instrução é baixo, o que acarreta diversos problemas, até a dificuldade de acesso à justiça. Além disso, o fato de a maioria ser estudante demonstra a falta de renda, o que promove a subordinação econômica ao homem e a continuação do relacionamento violento.

Em contrapartida, é de se dar realce para a circunstância de que, apesar da pouca instrução, essas mulheres possuem, pelo menos, o conhecimento de que existe uma proteção específica para as violências contra o gênero feminino. No mesmo apanhado, Moura, Albuquerque Netto e Souza (2012) reforçam essa ideia, afirmando que, em sua consulta, as mulheres entrevistadas sabiam da existência da lei, mesmo que de maneira superficial, o que é um fato positivo perante tantos dados contrários. Também, se vislumbrou que os ex-companheiros assumiram em 39\% das situações o papel de agressores, sendo que a convivência, em média, é de até um ano.

Denota-se que a maioria das vítimas não possui vínculo jurídico com os homens, o que indica que elas se sentem inseguras para adentrar ainda mais nos relacionamentos desgastantes, permanecendo com o estado civil inalterado. Podem-se entrelaçar as informações obtidas nessa pesquisa com o que discorre Sá (2011), a qual vislumbra que os agressores, em sua maioria, são ex-companheiros que não aceitam o término do relacionamento amoroso e, com o ego ferido, tendem a importunar e difamar as vítimas, com o intuito de prejudicá-las em todos os sentidos possíveis, sentindo-se, assim, realizados.

Depreende-se que a duração do relacionamento é pequena. Assim, é possível pensar em duas hipóteses, quais sejam: a) as mulheres tendem a perceber o cunho pejorativo e prejudicativo do relacionamento e buscam por findá-los em tempo hábil; ou, b) as mulheres, vítimas de longo prazo, preferem manter-se caladas a acionar o Judiciário, visando pôr fim às lides violentas do cotidiano. Pelo fato de o estudo abordar as relações sociais, deve-se sempre ponderar um meio termo, visto que, nesta Comarca, com base nos informes, a procura foi, eventualmente, mediana, tendo em vista o número de moradores.

Então, é evidente que a violência intrafamiliar abrange todas as classes sociais, bem como as mulheres, de uma maneira ampla, figuram como vítima das violências de todas as ordens. No entanto, o que se visualiza é que aquelas em idade ativa, sem dependentes, com baixa instrução, procuram auxílio e amparo, a fim de cessar, mesmo que momentaneamente, as situações desagradáveis que vivenciam em suas rotinas, tendo como figura principal seus ex-companheiros que as procuram ferir, através de ameaças. Isso reforça a existência das violências psicológica e simbólica intrafamiliares a partir deste perfil sociodemográfico.

Não se pode culpar a mulher por não buscar em terceiros o refúgio que o silêncio lhe proporciona. A ocultação da violência psicológica e simbólica que sofre tem como motivos fundantes 
a vergonha, a falta de amparo e o olhar desconfiado que muitos ainda lançam quando ela se sente oprimida por seu ascendente, descendente ou cônjuge. Há, mesmo na contemporaneidade, uma forte predominância da visão sexista, machista e patriarcal, uma vez que a mulher não consegue desobstaculizar estes padrões dominantes e acaba reproduzindo e naturalizando ainda mais o que está dado em termos de violência.

Tudo começa quando palavras e gestos ofensivos acabam contaminando a atmosfera de amor e paz que o relacionamento deveria conter. Humilhações, gestos grosseiros, que antes eram desconhecidos, tornam-se rotineiros e a mulher, na grande maioria das vezes, nem se dá conta desse caos sentimental em que passa a estar inserida. Ou seja, a mulher não percebe, efetivamente, que está sendo vítima de uma violência psicológica e simbólica, já que uma das consequências para perpetuação dessa situação é ela própria silenciar e ocultar o ocorrido.

Além da dependência afetiva, o poder econômico do agressor influencia muito na decisão de pôr fim ao relacionamento violento. Com isso, o segundo elemento fundante configura-se na situação econômica das vítimas, já que muitas mulheres não alcançam êxito para adentrar no mercado de trabalho, principalmente, pela falta de instrução/especialização. Como consequência, não se rompe com o ciclo desta violência.

Perfilhando a compreensão de Saffioti (1999a; 1999b), a subordinação econômica leva ao medo e, logicamente, ao silêncio e à ocultação das violências sofridas. E este silêncio compõe o ciclo da violência doméstica e intrafamiliar. A Cartilha do Ministério Público de São Paulo (2014), de maneira simples e atrativa, dispõe em 8 tópicos por quais motivos as mulheres permanecem caladas, quais sejam: 1. Medo de romper o relacionamento; 2. Vergonha de procurar ajuda e ser criticada; 3. Esperança de que o parceiro mude o comportamento; 4. Por sentir-se sozinha e não contar com pessoas que a apoiem; 5. Medo de não ser aceita na sociedade como uma mulher sem marido; 6. Dependência econômica dos parceiros para o sustento da família; 7. Nem todas estão preparadas para viver um processo de separação; e, 8. Por causa das relações desiguais de gênero.

No mesmo caminho, Soares (2005, p. 25-29) aborda oito razões que, em conjunto ou separadamente, podem levar a mulher a permanecer no relacionamento danoso. São elas: 1) o risco do rompimento - a mulher se sente insegura ao tentar se desvincular do relacionamento; 2 ) esperança que o companheiro mude o comportamento - a mulher permanece ao lado do agressor, por amor ou não, mesmo que o homem não opte por buscar ajuda, pois tem a expectativa de que a situação violenta se modificará; 3) Isolamento - a mulher restringe, forçadamente, suas relações sociais e familiares, pois o opressor, de um modo geral, é ciumento e possessivo; 4) negação social quando a vítima, ao pedir ajuda a um profissional, não se sente amparada e se encontra sob olhares desconfiados ou, até mesmo, percebe que falta atenção ao ouvir seus relatos, perdendo a esperança de ser acolhida.

Seguindo tal sequência, pode-se afirmar que também constituem motivos para a continuidade da ligação violenta: 5) vergonha e medo - são fatores que andam em conjunto, pois a mulher se sente envergonhada de deletar o próprio companheiro, achando que o relacionamento fracassou por sua culpa, além de estar presente o medo, motivador da não realização de mudanças; 6) as barreiras que impedem o rompimento - são diversas, trata-se, principalmente, de chantagens e de coações que o agressor usa para oprimir, como difamação, negação da pensão alimentícia, ameaças de morte, entre outras; 7) dependência econômica quando a pessoa é economicamente frágil, ela permanece à mercê; e, 8) o ato de deixar a relação é um longo processo e a mulher deve 
prepara-se para o afastamento emocional, física e materialmente. Tais iniciativas podem levar tempo para concretização, já que os esforços tendem a oscilar, devido ao amplo envolvimento (SOARES, 2005, p. 25-29).

Como se pode visualizar, a violência moral, na forma de ameaça, possui maior incidência.

$\mathrm{O}$ ciclo da violência, composto por três fases, não acontece com todas as vítimas, porém, majoritariamente, é verificada sua presença em relações danosas. A primeira fase é a construção da tensão no relacionamento, composta por delitos como ameaça, injúria, danos, possuindo período de duração indefinida, podendo ser prolongado ou não. A segunda fase é a da explosão da violência, em que a tensão atinge seu ponto máximo e ele perde o "controle", podendo ser o período mais curto, em que o agressor pratica delitos como ameaça, lesões, vias de fato, entre outros. E, logo depois, surge o arrependimento, a terceira fase, caracterizada pelas desculpas e presentes, pela lamentação do homem pelos atos danosos praticados contra a vítima (SOARES, 2005, p. 18-23). Nesse período, como relata Blay (2001, p. 86-88), os homens "se sentem no direito de continuar controlando aquelas que consideram 'suas' mulheres. É a propriedade do corpo, o controle da sexualidade feminina que é exigida”.

Pode-se complementar ainda com o que é enfatizado por Safiotti (1999a, p. 85), quando menciona que "a violência doméstica ocorre em uma relação afetiva, cuja ruptura demanda, via de regra, intervenção externa. Raramente uma mulher consegue desvincular-se de um homem violento sem auxílio externo”. Aqueles que acompanham o grupo social da vítima devem e podem reconhecer sinais evidentes de maus-tratos, violências psicológica e simbólica que afeta toda a família. A mulher passa a ter autoestima diminuída, descuidando-se de sua aparência e de sua vida, além de ficar mais propensa a doenças. Igualmente, se há envolvimento de crianças, elas tendem a reproduzir o comportamento agressivo do patriarca, propagando, então, a violência doméstica e a expandido de forma indireta. Assim, inúmeros são os elementos que contribuem para a não visibilização das violências cotidianas.

\section{CONSIDERAÇÕES FINAIS}

Ao longo da presente pesquisa, pode-se demonstrar, com a associação de dados e disposições doutrinárias, que a ocultação das violências e os segredos das ofendidas têm, sim, relação com a subordinação econômica, com o tempo de convívio com o agressor, com as barreiras sociais, com o medo e a insegurança de que ele não será punido e, até mesmo, com a retaliação que a própria família ocasiona à ofendida. Isso evidencia uma triste realidade mundial, em que a mulher se submete e aceita, de maneira indireta, agressões por falta de amparo, por não conhecer seus direitos ou, inclusive, por não saber distinguir conflitos familiares de violência intrafamiliar. Trata-se de mulheres adultas entre 23 a 27 anos de idade, solteiras, com instrução de Ensino Fundamental completo, sem filhos e dependentes, com profissões que não as permitem ter estabilidade econômica, muito menos proporciona a elas o empoderamento, tanto econômico, como emocional e afetivo. Esta é, portanto, uma amostra representativa das violências intrafamiliares ocorridas no município de Cruz Alta/RS, a partir da análise de 80 inquéritos policiais da $2^{\text {a }}$ Promotoria de Justiça Criminal da cidade.

Ademais, é possível elucidar que as vítimas de violências intrafamiliares precisam, primeiramente, estar conscientes de que aquele comportamento do companheiro não é natural, não é saudável. É importante, também, que saibam identificar que estão sofrendo violências, inclusive 
que a submissão a que estão expostas não condiz com a realidade que devem enfrentar, assim como sempre existe uma saída, por mais difícil que ela seja, a vontade de novamente viver em liberdade, fora do cárcere doméstico, deve ser perpetrada.

Assim, os segredos intrafamiliares podem ser evidenciados pela vítima, quando esta se sentir capaz de expor a situação vivenciada aos outros, fragilizando o agressor e o culpabilizando pelas atitudes agressivas. É claro que cada pessoa possui seu tempo de reação, mas, até mesmo aqueles que vivem na ingenuidade, podem um dia encontrar o caminho para se libertar da situação de violência. Há, portanto, muitos motivos que levam esta pesquisa a, qualitativamente, ingressar no caminho das visibilidades, a fim de que os segredos sejam revelados, servindo como um impulso a todas que necessitam compreender a subordinação que enfrentam e reconhecendo que o silêncio é um dos mais poderosos mecanismos de perpetuação da violência psicológica e simbólica feminina.

\section{REFERÊNCIAS}

BLAY, E. A. Um Caminho ainda em Construção: a igualdade de oportunidades para as mulheres. Revista USP, São Paulo, n. 49, p. 82-97, mar./maio 2001.

BOURDIEU, P. O Poder Simbólico. Rio de Janeiro: Bertrand Brasil, 1989.

BRASIL. Lei n. 11.340, de 07 de agosto de 2006. Cria mecanismos para coibir a violência doméstica e familiar contra a mulher […]. 21. ed. São Paulo: Saraiva, 2016.

CLIMACO, D. Das transformações da dominação masculina. Cadernos Pagu, Campinas, n. 30, p. 437443, jan./jun. 2008.

FERnANDES, M. da P. Sobrevivi... Posso Contar. 2.ed. Fortaleza: Armazém da Cultura, 2012.

JESUS, D. de. Violência Contra a Mulher: aspectos criminais da Lei n. 11.340/2006. 2. ed. São Paulo: Saraiva, 2015.

MARQUES, T. M. Violência Conjugal: estudo sobre a permanência da mulher em relacionamentos abusivos. 2005. 303f. Dissertação (Mestrado em Psicologia), Universidade Federal de Uberlândia, Uberlândia. 2005.

MINISTÉRIO PÚBLICO DO ESTADO DE SÃO PAULO. Cartilha "Mulher, Vire a Página... E seja Protagonista de um Final Feliz!”. São Paulo: MPSP, 2014.

MOURA, M. A. V.; ALBUQUERQUE NETTO, L. de; SOUZA, M. H. N. Perfil sociodemográfico de mulheres em situação de violência assistidas nas delegacias especializadas. Escola Anna Nery, Rio de Janeiro, v. 16, n. 3, p. 435-442, jul./set. 2012.

NARVAZ, M. G.; KOLLER, S. H. Metodologias Feministas e Estudos de Gênero. Psicologia em Estudo, Maringá, v. 11, n. 3, p. 647-654, set./dez. 2006.

PATEMAN, C. O Contrato Sexual. Rio de Janeiro: Paz e Terra, 1993.

RIBEIRO, D. de P. Violência Contra a Mulher: aspectos gerais e questões práticas da Lei n. ${ }^{\circ}$ 1 1.340/2006. Brasília: Gazeta Jurídica, 2013.

SÁ, S. D. Características Sociodemográficas e de Personalidade de Mulheres Vítimas de Violência Doméstica. 2011. 93f. Tese (Doutorado em Psicologia), Pontifícia Universidade Católica do Rio Grande do Sul, Porto Alegre. 2011. 
SAFFiOTI, H. I. B. O Poder do Macho. São Paulo: Moderna, 1987.

SAFFIOTI, H. I. B. Já se Mete a Colher em Briga de Marido e Mulher. São Paulo em Perspectiva, São Paulo, v. 13, n. 4, p. 89-91, dez. 1999a.

SAFFIOTI, H. I. B. Primórdios do Conceito de Gênero. Cadernos Pagu, Campinas, v. 12, p. 157-163, 1999b.

SILVA, L. L. da; COELHO, E. B. S.; CAPONI, S. N. C. de. Violência Silenciosa: violência psicológica como condição da violência física doméstica. Interface, Botucatu, v. 11, n. 21, p. 93-103, jan./abr. 2007.

SOARES, B. Enfrentando a Violência contra as Mulheres: orientações práticas para profissionais e voluntários. Brasília: Secretaria Especial de Políticas para as Mulheres, 2005.

ZANCAN, N.; WASSERMANN, V.; LIMA, G. Q. de. A violência doméstica a partir do discurso de mulheres agredidas. Pensando Famílias, Porto Alegre, v. 17, n. 1, p. 63-76, jul. 2013. 